\title{
Possibility of using embryonic neural cells to regenerate structures of the inner ear of Guinea pigs after experimental ototoxicosis
}

\author{
Iryna Ihorivna SAPIZHAK ${ }^{1}$, V. PYSANKOํㅜ, T. MALYSHEVA² \\ 1 "O.S. Kolomiychenko" Institute of Otolaryngology of the National Academy of Medical Sciences of Ukraine, \\ Kiev, Ukraine \\ 2 "Romodanov" Neurosurgery Institute of the National Academy of Medical Sciences of Ukraine, Kiev, Ukraine
}

\begin{abstract}
Hearing disorders greatly impair the comfort of life, change a person's emotional state, and when developed in early childhood lead to disorders of psycho-social formation of personality. There are currently no effective treatments for patients with sensorineural hearing loss (SNHL). Therefore, all over the world prefer "substitution tactics", namely - hearing aids for deafness, or cochlear implant for deafness.

Aim. To evaluate the influence of NEC in different ways of their introduction on the morphological state of the structures of the inner ear (Corti's organ and the first neuron, vascular strip), as well as the auditory nerve on the background of aminoglycoside ototoxicosis. To investigate the characteristics and directions of reorganization of hemoblood supply and features of cyto - and myeloarchitectonics of structures of the inner ear.

Materials and methods. To study the effectiveness of neuronal embryonic cells (NEC) in aminoglycoside ototoxicosis, experimental studies were performed on 40 guinea pigs weighing from 500 to $600 \mathrm{~g}$. SNHL was caused by the introduction of aminoglycoside antibiotic - gentamicin sulfate at a dose of $100 \mathrm{mg} / \mathrm{kg}$ for 14 days. The neuronal stem cell suspension was administered in a volume of 2 million cells in $0.5 \mathrm{ml}$ intratympanically and 2 million cells in $0.5 \mathrm{ml}$ suboccipitally on days 1 and 15 of the experiment.

Results and discussion. The influence of NEC on different methods of their introduction on the morphological state of the structures of the inner ear (Corti's organ and the first neuron), as well as the auditory nerve on the background of aminoglycoside ototoxicosis was evaluated. The characteristics and directions of reorganization of hemoblood supply and features of cyto - and myeloarchitectonics of structures of an inner ear according to an estimation of neurovasal relations are investigated.

Conclusions. The data obtained indicate that intratympanic and suboccipital administration of NEC promotes the regeneration of damaged cell structures of the inner ear. This opens the prospect of using NEC to develop new approaches in the treatment of patients with sensorineural hearing loss.
\end{abstract}

Keywords: neuronal steam cells, sensoneural hearing loss, Guinea pigs

\section{INTRODUCTION}

Sensorineural hearing loss (SNHL) combines diseases of the inner ear and nerve pathways to the auditory cortex. The most common damaging factors that often lead to the development of this disease include genetic disorders, including hereditary, autoimmune processes, bacterial and viral infections, ototoxic drugs, and so on. At the same time, the lack of effectiveness of drug treatment with this hearing impairment, despite the 
large number of proposed methods, forces us to look for new ways to solve this problem.

Our previous studies have shown the possibility of improving sound perception by intratympanic and suboccipital administration of neuronal embryonic cells to guinea pigs under conditions of aminoglycoside ototoxicosis [1].

Stem cell therapy is developing rapidly and has great potential for use in the treatment of various degenerative diseases of the nervous system, including sensorineural hearing loss in one of the first stages of patients with deafness and deafness. [2-5].

The first attempts to study the possibility of stem cells in the treatment of functional disorders of the inner ear were made by Nishimura et al. [6]. They showed that transplanted NECs can survive in the inner ear and differentiate into phenotypes of neuronal cells, glial and hair.

Magomedov $[7,8]$ was one of the first who applied embryonic disturbances at people in the form of homogenate of embryonic cells. Observations were performed on 14 patients with neurosensory deafness IIIII degrees with a disease duration of 6 months to 3 years. After a single application, there was an improvement in hearing according to the tone threshold audiometry, on average by $10 \mathrm{~dB}$ and audiometry in the extended frequency range by $5 \mathrm{~dB}$.

\section{MATERIALS AND METHODS}

To study the effectiveness of NEC in aminoglycoside ototoxicosis, experimental studies were performed on 40 guinea pigs weighing from 500 to $600 \mathrm{~g}$. SNHL was caused by the administration of aminoglycoside antibiotic - gentamicin sulfate - at a dose of $100 \mathrm{mg} / \mathrm{kg}$ for 14 days. Neuronal stem cell suspension was administered in a volume of 2 million cells in $0.5 \mathrm{ml}$ intratympanically and 2 million cells in $0.5 \mathrm{ml}$ suboccipitally on days 1 and 15 of the experiment. All guinea pigs were divided into groups for research.

Group 1 (5 animals) - modeling of aminoglycoside ototoxicosis.

Group 2 (5 animals) - intratympanic administration of NEC on the 15th day after gentamicin ototoxicosis.

Group 3 (5 animals) - suboccipital administration of NEC on the 15th day of gentamicin ototoxicosis.

Group 4 (5 animals) - intratympanic administration of NEC for 1 day of gentamicin ototoxicosis.

Group 5 (5 animals) - suboccipital administration of NEC for 1 day of gentamicin ototoxicosis.

Group 6 (5 animals) - control 2 - administration of sodium chloride solution $0.9 \%$ intramuscularly once daily for 14 days.

All animals were examined at the beginning of the experiment, before the administration of NEC and at the end of the study for hearing by the method of registration of short-latency auditory evoked potentials (SAEPs). Removal of guinea pigs from the experiment was performed under thiopental - sodium anesthesia at a dose of $20 \mathrm{mg} / \mathrm{kg}$ body weight. After guillotine decapitation, blocks of temporal bones were isolated, fixed in ascending concentrations of $5-7-10 \%$ of buffered formalin solution for further morphological and electron microscopic examination.

The experiments were performed in accordance with the General Principles of Animal Experimentation, approved by the III National Congress on Bioethics and in accordance with the provisions of the European Convention for the Protection of Vertebrate Animals Used for Experimental and Other Scientific Purposes.

The pathological process of deafness was simulated using an ototoxic antibiotic of the aminoglycoside group - gentamicin sulfate, which was administered at a rate of $100 \mathrm{mg} / \mathrm{kg}$ intramuscularly daily for 14 days.

To prepare a culture of allogeneic neuronal stem cells, guinea pig fetuses 14 days of gestation were obtained from pregnant females under general anesthesia (ketamine-xylazine and ether anesthesia) by hysterectomy.

Histological examination of the tissue obtained after withdrawal from the experiment and layer-by-layer preparation of the temporal bone with the selection of the structures of the inner ear. After macro and microscopic examination, the obtained fragments of ganglion tissue and acoustic nerve (different zones of distance from the curl) were fixed in the cooled at a temperature of $+4{ }^{\circ} \mathrm{C}$ neutral (buffered) formalin of increasing concentration (4-7\% - 10\%) not more than 24 hours and poured into paraffin (according to standard methods). Serial microtome sections $(5 \mu \mathrm{m})$ were stained with review techniques (hematoxylin-eosin, hematoxylin-picrofuxin) and special (Kulchitsky method) and immunohistochemical techniques. Immunohistochemical study (observations) (panel was determined after preliminary morphological analysis) was performed using standard streptovidin-biotin peroxidase complex and monoclonal antibodies (VEGF, CD99, Ki67) in spent working dilutions. Histological sections were stained with Mayer's hematoxylin and enclosed in balm.

\section{RESULTS}

In the group of animals with 14-day administration of gentamicin sulfate (group 1) in the study of the structures of the auditory receptor and the auditory nerve there are pronounced degenerative changes. Irritation is expressed in nerve fibers, which is manifested by dyschromia and focal swelling. In some axons there are phenomena of ascending degeneration - 
they are divided into ovoids of relatively large size nonspecific degenerative destructive changes (Fig. 1).

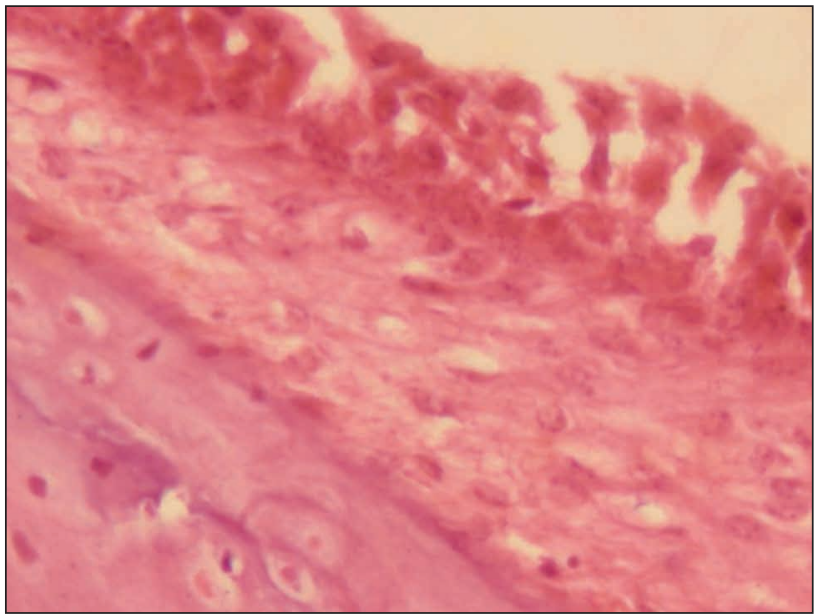

FIGURE 1. Experiment: Aminoglycoside intoxication (14

days) Degenerative-dystrophic changes of the epithelium and tectorial membrane. Hematoxylin-eosin staining, $400 x$

In the structures of the vascular strip there was a pronounced swelling of the connective tissue, dilated blood vessels, a significant number of which are full of formed elements of blood. Stasis is noted in many venules (Fig. 2).

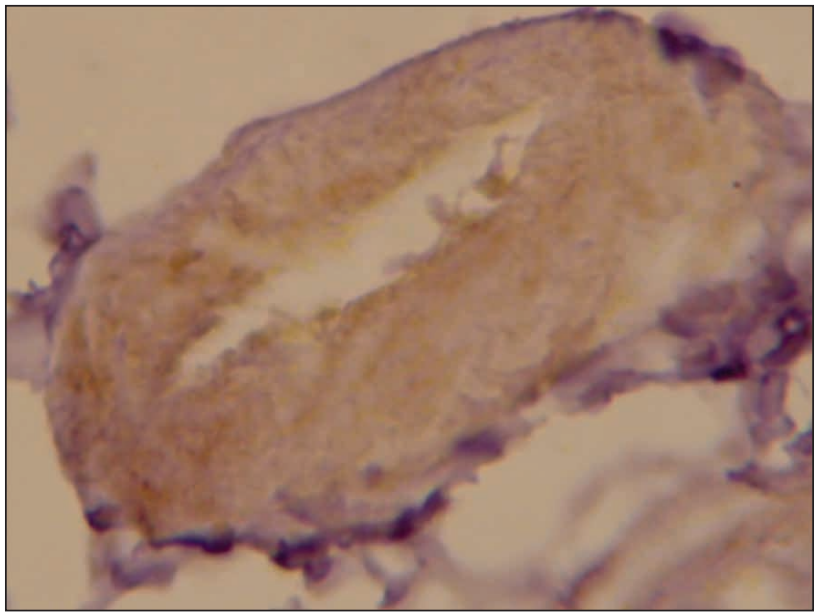

FIGURE 2. Dystrophic changes (fibrinoid necrosis) of the arteriole wall in the absence of signs of vascular wall cell proliferation. Immunophenotyping with anti-BP to Ki67 with Mayer hematoxylin staining, $800 x$

After 14 intramuscular injections of gentamicin sulfate in the area of the proximal segment of the vestibulo-cochlear nerve, typical manifestations of the reaction of tissue elements of the nerve to damage are determined. Swelling of the connective tissue, paretically dilated blood vessels, a significant number of which are full of formed elements of blood. The diameter of the axons is increased, the number of neurolemocytes in these fibers is greater than in the control of proliferative parameters. A significant number of hy- perchromic grains are found in the cytoplasm of Schwann cells (Fig. 3).

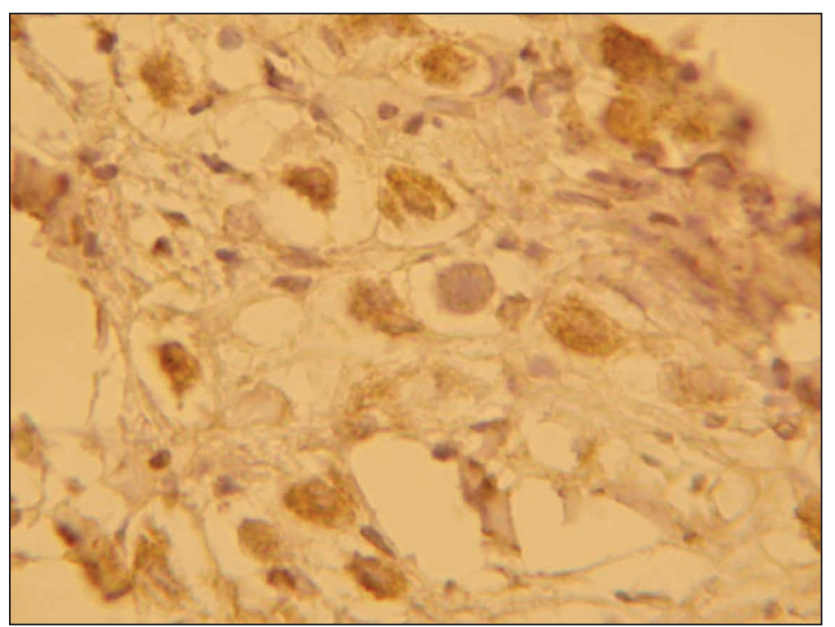

FIGURE 3. Degenerative-dystrophic changes in the absence of SC. Immunophenotyping with anti-BP to C -99 with Mayer hematoxylin staining, $800 x$

After intratympanic administration of NEC on the first day of the experiment (group 4), the presence of a significant number of fibrin threads with single macrophagocytes, lymphocytes, tissue basophils is noted. A significant number of hyperchromic grains are found in the cytoplasm of Schwann cells (Fig. 4).

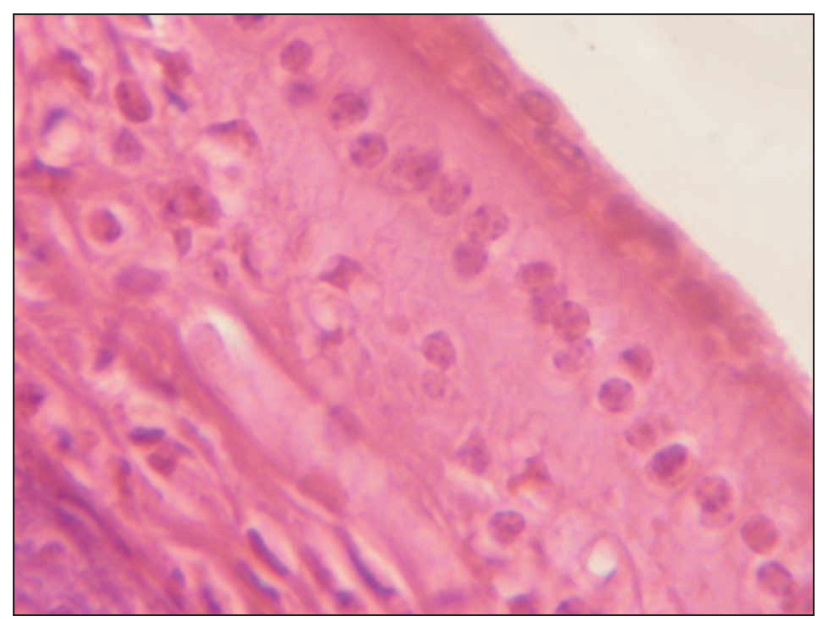

FIGURE 4. Introduction of NEC intratympanically for 1 day. Internal hair cells on the apical surface - contoured stereocilia, vasodilation, enlargement of the stroma histiocytes. Homogenization of amorphous substance. Hematoxylin-eosin staining, $800 x$

Newly formed capillaries with a large lumen and swollen endotheliocytes with signs of remodeling are found in the vascular strip near the site of NEC injection (Fig. 5). In this area there are signs of activation of regeneration of individual areas of nerve fibers (change of spatial linear location - discomplexation). The microvessels of the distal segment are dilated. Tissue basophils and histiocytes are located perivasally. 


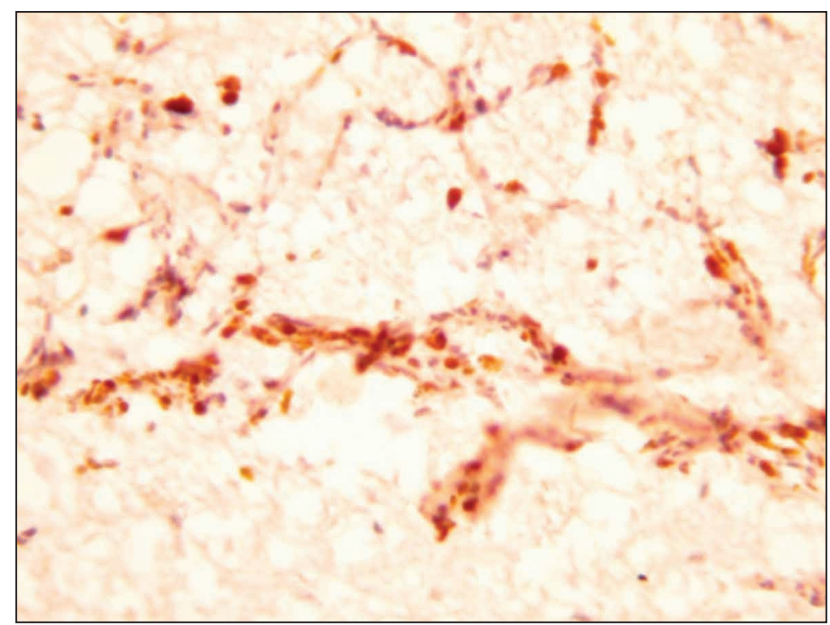

FIGURE 5. Restoration of the vascular component in the vascular strip (capillary link modeling) coexpression VGFR + Ki-67 Immunophenotyping with Mayer hematoxylin staining, $200 x$

In the first ganglion there is a restoration of histoarchitectonics, due to the appearance of fibroblasts with increased basophilia of the cytoplasm, the presence of large nuclei and nucleoli (Fig. 6).

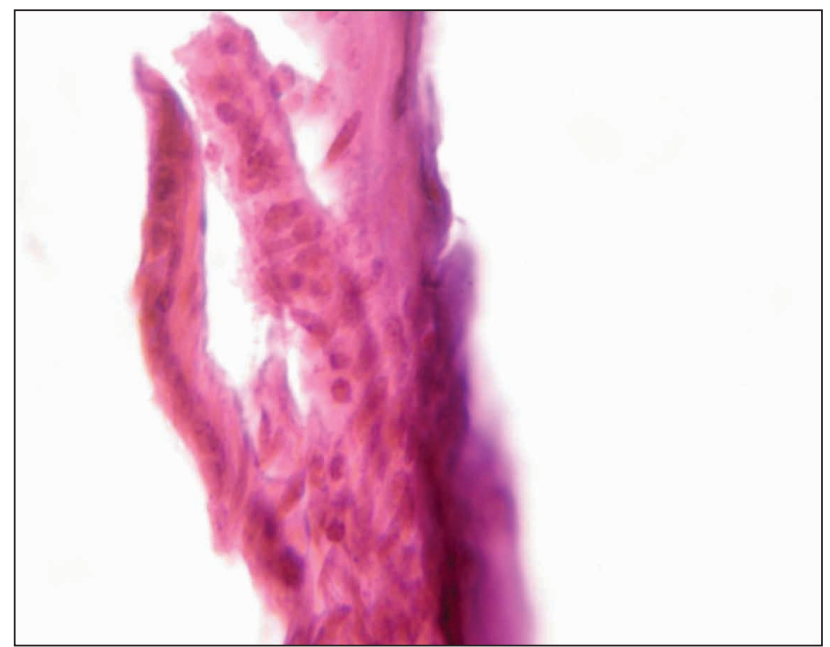

FIGURE 6. Introduction of NEC intratympanically (1 day) organon spirale restoration of histoarchitectonics. Hematoxylineosin staining, $400 x$

After intratympanic administration of NEC on the 15th day of gentamicin ototoxicosis (group II), we noted signs of regeneration of varying severity. The diameter of their axons is increased, a significant part of them was at the end of the growth bulb. The number of Schwann cells in the mentioned nerve fibers was greater than in the control (Fig. 7).

After administration of NEC, the presence of transplanted cells of immunopositive CD - 99, which are placed quite compactly (Fig. 8). There is a small amount of fibrin around the groups of cells of the embryonic nervous tissue and single macrophages and histiocytes, lymphocytes, tissue basophils compared to control.

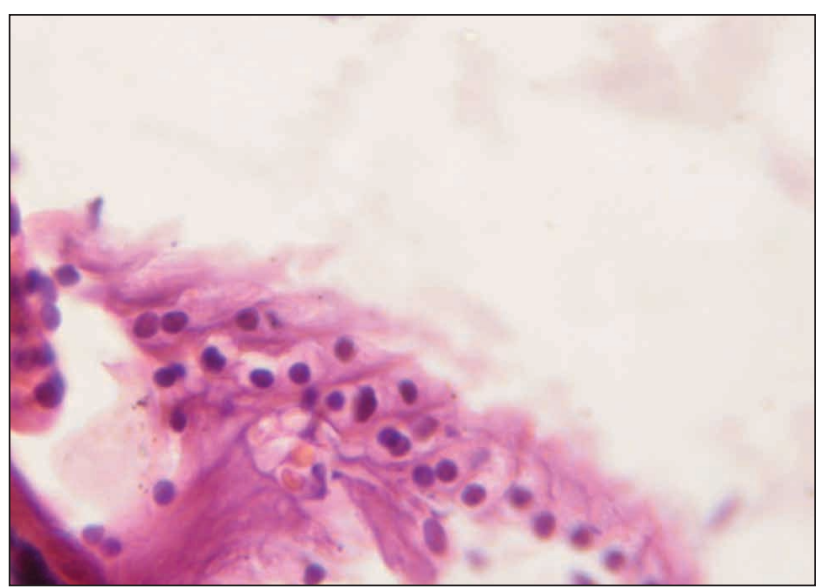

FIGURE 7. Introduction of NEC for 15 days intratympanically - restoration of structure and spatial orientation of hair cells innervated by dendrites of spiral ganglion neurons. Hematoxylin-eosin staining, $800 x$

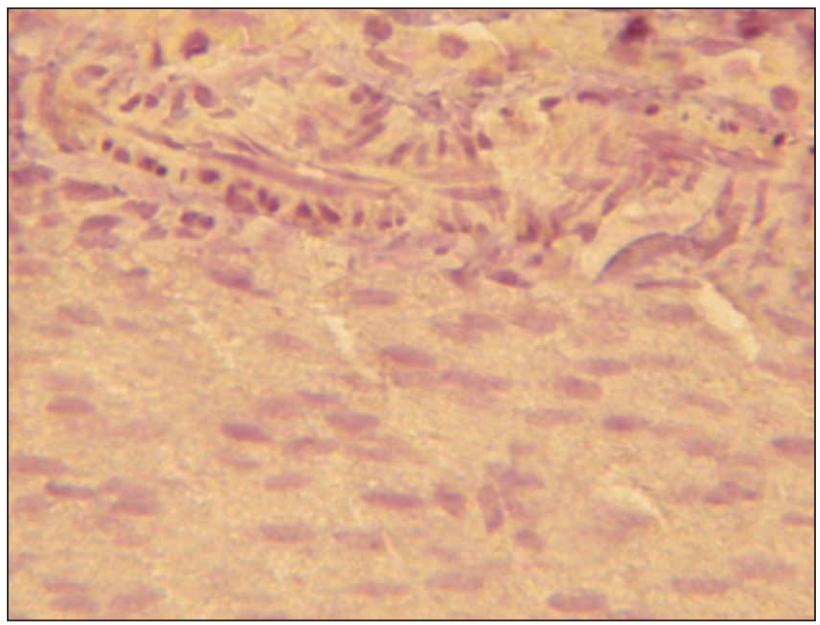

FIGURE 8. Immunophenotyping with anti-BP to CD-99 with Mayer hematoxylin staining, $200 x$

Signs of regeneration are already noted in the main number of nerve fibers. The microvessels of the distal segment are dilated, although the phenomena of stasis and perivascular edema are not pronounced. The location of the vessels is quite orderly - their bulk is located along the axis of the nerve. Axons are thickened, the diameter of the fibers is relatively larger than in the previous group, fibers with a larger diameter are more common. In the composition of nerve fibers that regenerate an increased number of nuclei of neurolemocytes.

In group 3 experimental animals, which were injected suboccipital NEC on the 15th day of the experiment in the proximal segment of the damaged nerve trunk, the degree of previously marked connective tissue changes decreases, some blood vessels - dilated with stasis, signs of perivasal edema. Most fibroblasts are characterized by increased cytoplasmic basophilia, the presence of large nuclei and nucleoli. In general, nerve structures, especially the fibers of the distal segment 
are more morphologically mature than in the control (Fig. 9 and 10).

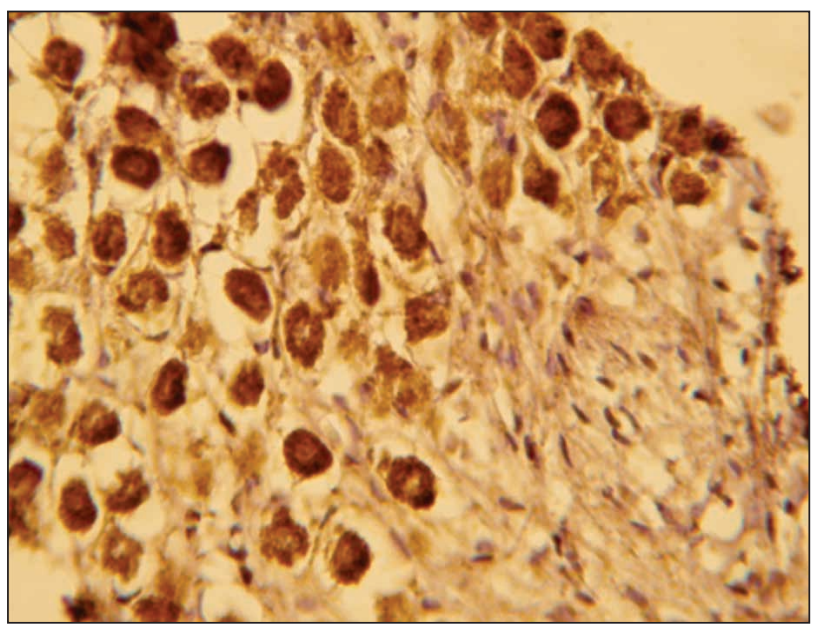

FIGURE 9. Administration of NEC suboccipitally for 15 days. There is an increase in reparations. Immunophenotyping with anti-BP to CD-99 with Mayer hematoxylin staining, 200x

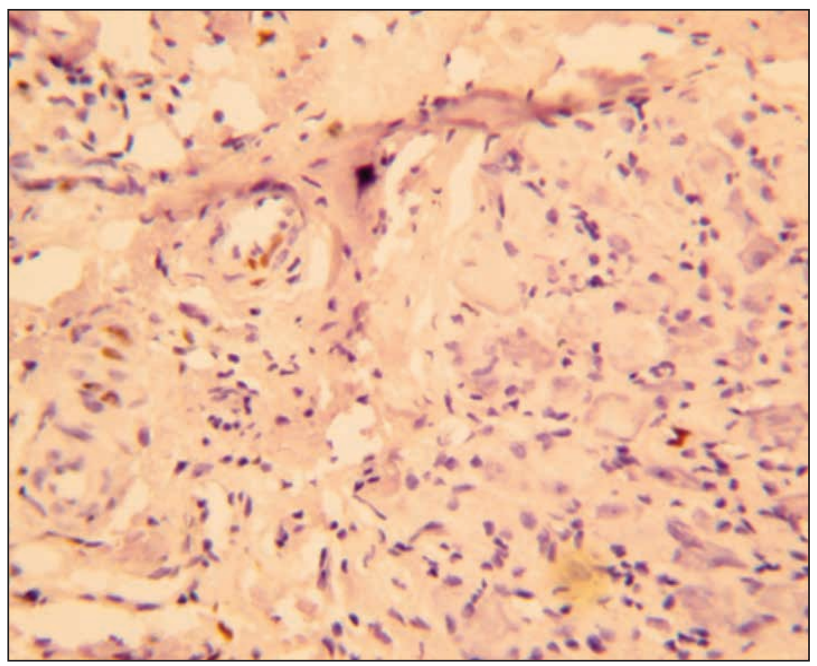

FIGURE 10. Administration of NEC suboccipitally on the 15th day of the experiment stria vascularis; restoration of the characteristic pattern with activation of proliferation. Immunophenotyping with anti-BP to $\mathrm{Cl}-67$ ) with Mayer hematoxylin staining

\section{DISCUSSIONS}

Over the past 15 years, significant progress has been made in the use of stem cells in the treatment of the inner ear. Although cell types and transplantation methodology differed in different laboratories, they all report the survival of transplanted cells for 3-9 weeks after administration [9-12].

Based on previous studies using guinea pig models, we decided to introduce cells by intratympanic and suboccipital injections [1].

A number of authors injected cells directly into the scala tmpany. They expected that the chosen approach will ensure efficient delivery of cells proximal to the base (SGNs in the Rosenthal channel) while minimizing mechanical damage to the cytoarchitecture of the snail. Previous studies have also reported the survival of exogenous cells in the mammalian snail for short periods of time [13-17].

In particular, these studies reported a decrease in the number of stem cells transplanted into the guinea pig scala tmpany between 2 and 4 weeks in vivo [18]. When counting, the number of surviving cells decreased after 4 weeks in vivo. According to Iguchi et al. (2003), approximately $10 \%$ of nerve stem cells administrated to the mouse snail were detected 4 weeks after transplantation [14]. Quantitative data from this study also show a significant reduction in the number of cells in the inner ear between 2 and 4 weeks in vivo. The reason for this decrease in cell survival after 4 weeks in vivo is unclear, but we suggest that this may be due to both the place of delivery and the presence of cochlear aqueduct - the channel that connects the fluid-filled inner ear with cerebrospinal fluid (CSF).

The results of research show that the administration of cell suspensions to the snail through the skala tympany is not the most suitable, in our opinion, a surgical approach for long-term cell replacement therapy.

Although stem cells have been able to survive for up to 4 weeks in the snail, the widespread cell division and low cell count found in the target area is not ideal. In addition, the surgical approach used by researchers is difficult and traumatic because in most cases the modiolus is damaged, for long-term use. That is why we consider promising the use of intratympanic and suboccipital method of NEC administration, as the least traumatic for cytoarchitectonics curls surgical method of delivery of the suspension into the inner ear, for long-term cell therapy of sensorineural hearing loss.

We observed regenerative processes in all structures of the inner ear, which were damaged by ototoxic antibiotic (vascular strip, spiral ganglion, proximal segment of the vestibulo-cochlear nerve).

Thus, our results in comparison with the literature indicate the active migration of embryonic cells after subocytopenic and intratympanic injection, as well as the prospects of using this method of administration of NEC.

\section{CONCLUSIONS}

Summarizing the data obtained by light microscopy, we found that the histological picture of the qualitative signs of the regenerative process in the studied groups was as follows: the best regeneration occurred in the group with intratympanic and suboccipital administration of NEC on the 15th day of gentamicin ototoxicosis, which was mainly due to better vascularization, greater activity of Schwann cells, less reaction of the elements 
of the connective tissue environment, compared with the control. The best regeneration occurred in the group with suboccipital administration of NEC, which was mainly due to better vascularization, faster resorp- tion of myelin degradation products, greater activity of Schwann cells, less reaction of connective tissue environment compared to control.

Conflict of interest: none declared Financial support: none declared

\section{REFERENCES}

1. Sapizhak II, Timen HE, Semenova VM, Stayno LP. The neuronal stem cells effect on inner ear structure in experimental gentamicin ototoxicity. Ukrainian Neurosurgical Journal. 2017;4:55-59.

2. Chaykovskyi YuB, Dyeltsova O, Herashchenko S. Brain stem cells in the postnatal period. World of Medicine and Biology. 2011;4:148-153.

3. Groves AK. The challenge of hair cells regeneration. Exp Biol Med (Maywood). 2010 Apr;235(4):434-46.

4. Semenova VM, Lyubych LD, Lisyany NI, Glavatskiy AY, Stayno LP. Investigation of rat progenitor neural cells supernatant antitumor action on glioma cells in conditions of culture. Ukrainian Neurosurgical Journal. 2008;4:63-67.

5. Mendez I, Hong M, Smith S, Dagher A, Desrosiers J. Neural transplantation cannula and microinjector system: experimental and clinical experience. Technical note. J Neurosurg. 2000 Mar;92(3):493-9.

6. Nishimura K, Nakagawa T, Ono K, Ogita H, Sakamoto T, Yamamoto N, Okita K, Yamanaka S, Ito J. Transplantation of mouse induced pluripotent stem cells into the cochlea. Neuroreport. 2009 Sep 23;20(14):1250-4.

7. Magomedov M. Use of fetal tissue in otolaryngology. Analysis of problem and future. Bulletin Otorhinolaryngology. 1998;2:16-23.

8. Magomedov M. Application of fetal tissues in the treatment of chronic sensorineural hearing loss. Proceedings of International Scientific Conference Dedicated to the 75th anniversary of the Department of Otolaryngology of Dnepropetrovsk and Clinics of Medical Academies. Dnipropetrovsk; 1997.

9. Hildebrand MS, Dahl HH, Hardman J, Coleman B, Shepherd RK, de Silva MG. Survival of partially differentiated mouse embryonic stem cells in the scala media of the guinea pig cochlea. J Assoc Res Otolaryngol. 2005 Dec;6(4):341-54.

10. Hu Z, Andäng M, Ni D, Ulfendahl M. Neural cograft stimulates the survival and differentiation of embryonic stem cells in the adult mammalian auditory system. Brain Res. 2005 Jul 27;1051(1-2):137-44.

11. Hu Z, Ulfendahl M, Olivius NP. Survival of neuronal tissue following xenograft implantation into the adult rat inner ear. Exp Neurol. 2004 Jan;185(1):7-14.

12. Hu Z, Wei D, Johansson CB, Holmström N, Duan M, Frisén J, Ulfendahl M. Survival and neural differentiation of adult neural stem cells transplanted into the mature inner ear. Exp Cell Res. 2005 Jan 1;302(1):40-7.
13. Huisman MA, Rivolta MN. Neural crest stem cells and their potential application in a therapy for deafness. Front Biosci (Schol Ed). 2012 Jan 1;4:121-32.

14. Iguchi F, Nakagawa T, Tateya I, Kim TS, Endo T, Taniguchi Z, Naito Y, Ito J. Trophic support of mouse inner ear by neural stem cell transplantation. Neuroreport. 2003 Jan 20;14(1):77-80.

15. Ito J, Kojima K, Kawaguchi S. Survival of neural stem cells in the cochlea. Acta Otolaryngol. 2001 Jan;121(2):140-2.

16. Naito $Y$, Nakamura T, Nakagawa $T$, Iguchi $F$, Endo T, Fujino K, Kim TS, Hiratsuka Y, Tamura T, Kanemaru S, Shimizu Y, Ito J. Transplantation of bone marrow stromal cells into the cochlea of chinchillas. Neuroreport. 2004 Jan 19;15(1):1-4.

17. Olivius P, Alexandrov L, Miller J, Ulfendahl $M$, Bagger-Sjöbäck D, Kozlova EN. Allografted fetal dorsal root ganglion neuronal survival in the guinea pig cochlea. Brain Res. 2003 Jul 25;979(1-2):1-6.

18. Tateya I, Nakagawa T, Iguchi F, Kim TS, Endo T, Yamada S, Kageyama R, Naito Y, Ito J. Fate of neural stem cells grafted into injured inner ears of mice. Neuroreport. 2003 Sep 15;14(13):1677-81. 